Journal of Sol-Gel Science and Technology 1:177-184 (1994).

(c) Kluwer Academic Publishers. Manufactured in The Netherlands.

\title{
Sol-Gel $\mathrm{ZrO}_{2}$ Coatings for Chemical Protection of Stainless Steel
}

\author{
PEDRO DE LIMA NETO, MOHAMED ATIK, LUIS A. AVACA, AND MICHEL A. AEGERTER \\ Institute of Physics and Chemistry of Säo Carlos, University of Săo Paulo, CX. Postal 369, 13560-970-Săo \\ Carlos (SP), Brazil
}

\begin{abstract}
ZrO}_{2}$ coatings deposited on $316 \mathrm{~L}$ stainless steel sheets were synthesized by sol-gel method using $\mathrm{Zr}\left(\mathrm{OC}_{3} \mathrm{H}_{7}\right)_{4}$ as precursor and isopropanol, glacial acetic acid, and water as solvents for application with ultrasounds. Different solutions for dip-coating were prepared with compositions varying between 0.025 and $0.9 \mathrm{~mol} / \mathrm{dm}^{3}$ of $\mathrm{ZrO}_{2}$. X-ray diffraction shows that the films densified at $800^{\circ} \mathrm{C}$ are crystalline with a tetragonal structure. The thickness of the coatings varied from $0.35-0.75$ $\mu \mathrm{m}$. The influence of the $\mathrm{ZrO}_{2}$ coatings on the corrosion behavior of stainless steel substrates in aqueous $\mathrm{NaCl}$ was studied through potentiodynamic polarization curves at $1 \mathrm{mV} / \mathrm{s}$. The values of the electrochemical parameters allow for an explanation of the role of the films in the increased resistance of steel against corrosion in moderately aggressive environments.
\end{abstract}

Key words: sol-gel coatings, chemical protection, stainless steel, $\mathrm{ZrO}_{2}$, corrosion

\section{Introduction}

Sol-gel methods are now widely used for preparing inorganic materials from solutions containing metal compounds such as metal alkoxides, metal acetylacetonates, inorganic compounds, etc., with water as hydrolysing agent and alcohols as solvent $[1,2]$. The fabrication of films via these methods offers potential advantages over traditional techniques such as low temperature processing, easy coating of large surfaces, easy adjustment of films thickness, high optical quality, low cost of processing infrastructure, large variety of deposition techniques (dip-, spin-, and spray-coating and electrophorese), etc. [3-5].

The chemical processing and the technical applications of sol-gel films have been recently reviewed by Schmidt [6] and Sakka and Yoko [7], respectively. A great variety of coating films have already been prepared by the sol-gel methods, and their properties have been used or proposed for various purposes which encompass applications in optical, electronic, optoelectronic, photonic, biotechnological, chemical, and mechanical fields.

The preparation and characterization of solgel films having specific chemical functions have been scarcely studied. Sol-gel films of $\mathrm{TiO}_{2}$
$[8,9], \mathrm{SrTiO}_{3}[10], \mathrm{BaTiO}_{3}[10], \alpha-\mathrm{Fe}_{2} \mathrm{O}_{3}$ [11], and $\mathrm{NiFe}_{2} \mathrm{O}_{4}$ [12] compositions exhibit interesting photoelectrochemical properties as catalysts for hydrogen generation by decomposition of water. $\mathrm{Al}_{2} \mathrm{O}_{3}: \mathrm{Pt}$ [13]; $\mathrm{TiO}_{2}: \mathrm{Pd}$ [14]; and $\mathrm{SiO}_{2}$ $\left(\mathrm{TiO}_{2}\right.$ or $\left.\mathrm{Al}_{2} \mathrm{O}_{3}\right): \mathrm{Fe}, \mathrm{Co}$, or $\mathrm{Ni}$ [15-17] are promising for catalysis application. The main efforts, however, have been realized in the field of chemical protection against acid and air corrosion, which cost millions of US dollars to society annually. Films such as $\mathrm{Al}_{2} \mathrm{O}_{3}$ [18], Si$\mathrm{O}-\mathrm{N}$, and $\mathrm{Si}_{3} \mathrm{~N}_{4}[19,20]$ can be used for semiconductor passivation. $\mathrm{SiO}_{2}$ is well known to prevent alkali diffusion and may be used as an intermediate coating between alkali glass and another functional coating [21] or to protect $\mathrm{Si}$ wafers [22]. $\mathrm{TiO}_{2}-\mathrm{CeO}_{2}[23,24], \mathrm{SiO}_{2}-\mathrm{TiO}_{2}-$ $\mathrm{ZrO}_{2}$ [25], and $\mathrm{TiO}_{2}-\mathrm{B}_{2} \mathrm{O}_{3}$ [26] have been used to protect glasses, and $\mathrm{SiO}_{2}, \mathrm{SiO}_{2}-\mathrm{Al}_{2} \mathrm{O}_{3}, \mathrm{TiO}_{2}$, and $\mathrm{SiO}_{2}-\mathrm{B}_{2} \mathrm{O}_{3}-\mathrm{Al}_{2} \mathrm{O}_{3}-\mathrm{BaO}$ have been shown to offer good corrosion protection for $\mathrm{Ag}$ mirrors [27]. The prevention of chemical corrosion and oxidation of mild steel, carbon steel, and various types of stainless steel has been tested with $\mathrm{SiO}_{2}$ [28], $\mathrm{SiO}_{2}-\mathrm{B}_{2} \mathrm{O}_{3}[29,30]$, mulite $\left(2 \mathrm{SiO}_{2}\right.$ $3 \mathrm{Al}_{2} \mathrm{O}_{3}$ ) [31], $\mathrm{ZrO}_{2}$ [32-37], MTOS [38], and $\mathrm{ZrO}_{2}-\mathrm{CeO}_{2}$ [39]. All these coatings increase the protection of metal substrates from air ox- 
idation (tested up to $800^{\circ} \mathrm{C}$ ) and acid attack (tested up to $90^{\circ} \mathrm{C}$ ).

The corrosion protection is strongly dependent on the thickness of the film and its structural quality. The presence of cracks and pores definitively degrades its efficiency. The most promising prevention for stainless steel so far has been reported by Atik, Aegerter, and Zarzycki using $\mathrm{ZrO}_{2}, \mathrm{TiO}_{2}-\mathrm{SiO}_{2}, \mathrm{SiO}_{2}-\mathrm{Al}_{2} \mathrm{O}_{3}$, and $\mathrm{TiO}_{2-}$ $\mathrm{CeO}_{2}$ coatings $[32,33,35,40]$. These coatings have been fabricated by a dip-coating technique using a sol preparation envolving sonocatalysis. The characterization performed by measuring the weight loss $\left(\mathrm{H}_{2} \mathrm{SO}_{4}\right.$ corrosion $)$ and weight gain (air oxidation) of small sheets $\left(2 \times 4 \mathrm{~cm}^{2}\right)$ has shown excellent results even at high temperature.

In this paper we present the results of a systematic electrochemical corrosion study of $\mathrm{ZrO}_{2}$ films prepared by the same procedures and deposited on stainless steel $316 \mathrm{~L}$, a material widely used for marine and chemical industry environments [41]. The corrosion characteristics of the samples, either bare stainless steel or coated with $\mathrm{ZrO}_{2}$ of different thickness, were evaluated through potentiodynamic polarization curves obtained in aqueous $\mathrm{NaCl}$ solutions at room temperature and through analysis of the relevant electrochemical parameters.

\section{Experimental}

\subsection{Substrate}

The substrate used was $316 \mathrm{~L}$ stainless steel of composition (wt.\%): $67.25 \mathrm{Fe}, 18.55 \mathrm{Cr}, 11.16$ $\mathrm{Ni}, 2.01 \mathrm{Mo}, 0.026 \mathrm{Cu}, 0.15 \mathrm{Si}$, and $0.028 \mathrm{C}$. Samples $(3.0 \times 1.5 \times 0.1 \mathrm{~cm})$ were mechanically cut from large foils and then degreased ultrasonically in acetone.

\subsection{Preparation of the Films}

Zirconium propoxide $\mathrm{Zr}\left(\mathrm{OC}_{3} \mathrm{H}_{7}\right)_{4}$ was used as source of zirconia. The sol was prepared by dissolving the alkoxide in isopropanol $\left(\mathrm{C}_{3} \mathrm{H}_{7} \mathrm{OH}\right)$, to which a small amounts of acetic acid $\left(\mathrm{CH}_{3} \mathrm{OOH}\right)$ and excess water were added to complete the hydrolysis. The concentration of the starting alkoxide solutions varied between 0.025 , and $0.9 \mathrm{~mol} / 1 \mathrm{ZrO}_{2}$. The volume ratios $\mathrm{H}_{2} \mathrm{O} / \mathrm{C}_{3} \mathrm{H}_{7} \mathrm{OH}$ and $\mathrm{H}_{2} \mathrm{O} / \mathrm{CH}_{3} \mathrm{COOH}$ were 1 and 2 , respectively. The mixture was submitted to ultrasonic irradiation (sonicator W 385 Heat Systems-Ultrasonics, Inc., $20 \mathrm{KHz}$ ). After $20 \mathrm{~min}$, the liquid became homogeneous and transparent; the sols were found stable for up to four weeks at room temperature when kept in a closed vessel.

Dip-coated samples were prepared by withdrawing the substrates from the sonosolutions at a constant rate of $10 \mathrm{~cm} / \mathrm{min}$. The resulting gel films were dried at $40^{\circ} \mathrm{C}$ for 15 minutes and then thermally treated at a rate of $5^{\circ} \mathrm{C} / \mathrm{min}$ with two isothermal holdings, the first at $400^{\circ} \mathrm{C}$ for 1 hour and the second at $800^{\circ} \mathrm{C}$ for 2 hours.

The thickness of $\mathrm{ZrO}_{2}$ coatings after heat treatment in air at $800^{\circ} \mathrm{C}$ for 2 hours varied beween $0.35 \mu \mathrm{m}$ and $0.75 \mu \mathrm{m}$, depending on the sol concentration. $\mathrm{ZrO}_{2}$ coated substrates sintered at that temperature with films having a thickness $\geq 0.67 \mu \mathrm{m}$ presented cracks. However, $\mathrm{ZrO}_{2}$ coatings thinner than $0.5 \mu \mathrm{m}$ were found continuous and visually crack free. For the present work, samples having film thicknesses of $0.5 \mu \mathrm{m}$ and $0.7 \mu \mathrm{m}$ were used, and their electrochemical behavior was compared to that of bare $316 \mathrm{~L}$ stainless steel plates.

\subsection{Characterization of the Films}

Analysis of coated substrates was made by using a Rigaku Rotaflex diffractometer with a characteristic $\mathrm{CuK}_{\alpha}$ radiation. X-ray diffraction data confirmed that the films densified at $800^{\circ} \mathrm{C}$ have the tetragonal $\mathrm{ZrO}_{2}$ structure (111 peak at d $=2.98 \AA$ ). A FTIR spectrometer with a 400 $4000 \mathrm{~cm}^{-1}$ range was used to obtain high resolution spectra of coatings; the measurements were performed by reflection at an incident angle of $30^{\circ}$. Unsintered samples show characteristic $\mathrm{OH}$ bands at $\sim 3600 \mathrm{~cm}^{-1}$, $\mathrm{Zr}-\mathrm{O}-\mathrm{C}$ groups at $1476.8 \mathrm{~cm}^{-1}$ and $1452.8 \mathrm{~cm}^{-1}$, and $\mathrm{Zr}-\mathrm{O}-\mathrm{Zr}$ at $665.7 \mathrm{~cm}^{-1}$. During sintering, the $\mathrm{OH}$ and $\mathrm{Zr}-\mathrm{O}-\mathrm{C}$ bands disappear and the $\mathrm{Zr}-\mathrm{O}-\mathrm{Zr}$ band increases strongly. Details of these analyses can be found elsewhere [32]. 


\subsection{Electrochemical Measurements}

A very convenient and precise way of evaluating the corrosion behavior of a material in a given medium is the recording of the complete polarization curve under potentiostatic control [42]. Thus, starting at the cathodic end, the electrode potential is anodically shifted in a continuous and slow fashion (e.g., $1 \mathrm{mV} / \mathrm{s}$ ) until the (anodic) current reaches a pre-established maximum value. By means of appropriate software, it is possible to determine the Tafel slope for both cathodic and anodic processes. Linear least-squares fitting of the experimental data to the Stern-Geary equation [42] determines the point at which the anodic and cathodic current densities are equal in magnitude, thus yielding a zero net current. This point defines the corrosion potential $\left(E_{\text {corr }}\right)$ as well as the corrosion current density $\left(i_{\text {corr }}\right)$.

The software also gives the polarization resistance $\left(R_{p}\right)$ of the system. This last value is obtained by analysis of the linear response $i$ vs. $E$ close to the corrosion potential, which in turn can also be determined using Tafel slopes [42]. For actively dissolving metals, the two values of $E_{c o r r}$ described above must coincide, whereas this is not the case when the anodic branch of the polarization curve shows a region of passive or quasi-passive behavior. In the later case, the meaningful value of $E_{\text {corr }}$ is that measured at $i \approx 0$ and not the one obtained by extrapolation of the Tafel lines. Finally, the calculations also furnish the corrosion rate (C.R.), which is a measure in mils per year (MPY) of the amount of metal being dissolved in the medium under consideration.

A comparison of $E_{\text {corr }}$ values for different materials in the same medium allows one to establish the relative stability of those materials with regard to corrosion. The more anodic the value of $E_{\text {corr }}$, the higher the corrosion resistance of the sample. A similar analysis could be done using the values of the corrosion current; in this case, however, it is necessary to be sure that the cathodic reaction (either hydrogen evolution or oxygen reduction) remains unchanged between experiments, since $i_{c o r r}$ is much more sensitive than $E_{\text {corr }}$ to small changes in the ca- thodic branch of the polarization curve.

In the present work, the electrochemical measurements were performed using a PAR Model 273 Potentiostat/Galvanostat linked to a microcomputer for data acquisition and handling through the PAR Model 342 Corrosion Measurement Software. The experiments were carried out at room temperature in air-saturated aqueous $\mathrm{NaCl}$ solutions of various concentrations. The working electrodes employed were $316 \mathrm{~L}$ stainless steel plates, either bare or coated with $\mathrm{ZrO}_{2}$ of $0.5 \mu \mathrm{m}$ and $0.7 \mu \mathrm{m}$ thickness, respectively, immersed $1 \mathrm{~cm}$ into the solution. A Pt-foil was the secondary electrode while the reference electrode was of the saturated calomel type (SCE).

\section{Results and Discussion}

Figures 1-3 show the complete polarization curves obtained for the three samples under investigation in aqueous $\mathrm{NaCl}$ solutions with concentrations 100,200 , and $300 \mathrm{~g} / \mathrm{dm}^{3}$, respectively. The curves were recorded a few minutes after immersion of the samples in order to allow stabilization of the system. Some experiments were also performed using $30 \mathrm{~g} / \mathrm{dm}^{3}$ $\mathrm{NaCl}$, which simply confirmed the trends observed with other solutions. In all cases, the cathodic branch of the curves shows a tendency towards a plateau, probably due to a limiting current controlled by $\mathrm{O}_{2}$ diffusion in the $\mathrm{NaCl}$ solutions. In contrast, the anodic branch of the curves changes drastically in the presence of the coatings. The observed effects do not follow a logical sequence with the electrolyte concentration and/or the $\mathrm{ZrO}_{2}$ film thickness, but in most cases the quasi-passive region shown by the bare $316 \mathrm{~L}$ stainless steel is disrupted. This is a indication that the pitting of the surface is altered in the presence of the films [42]. Meanwhile, the most marked effect of the coatings on the corrosion behavior of $316 \mathrm{~L}$ stainless steel is the shift of the corrosion potential towards more noble values. This shift, that in some cases amounts to $\sim 300 \mathrm{mV}$ (figure 2), is a clear indication of the protective properties of the films with regard to the corrosion of stainless steel in 


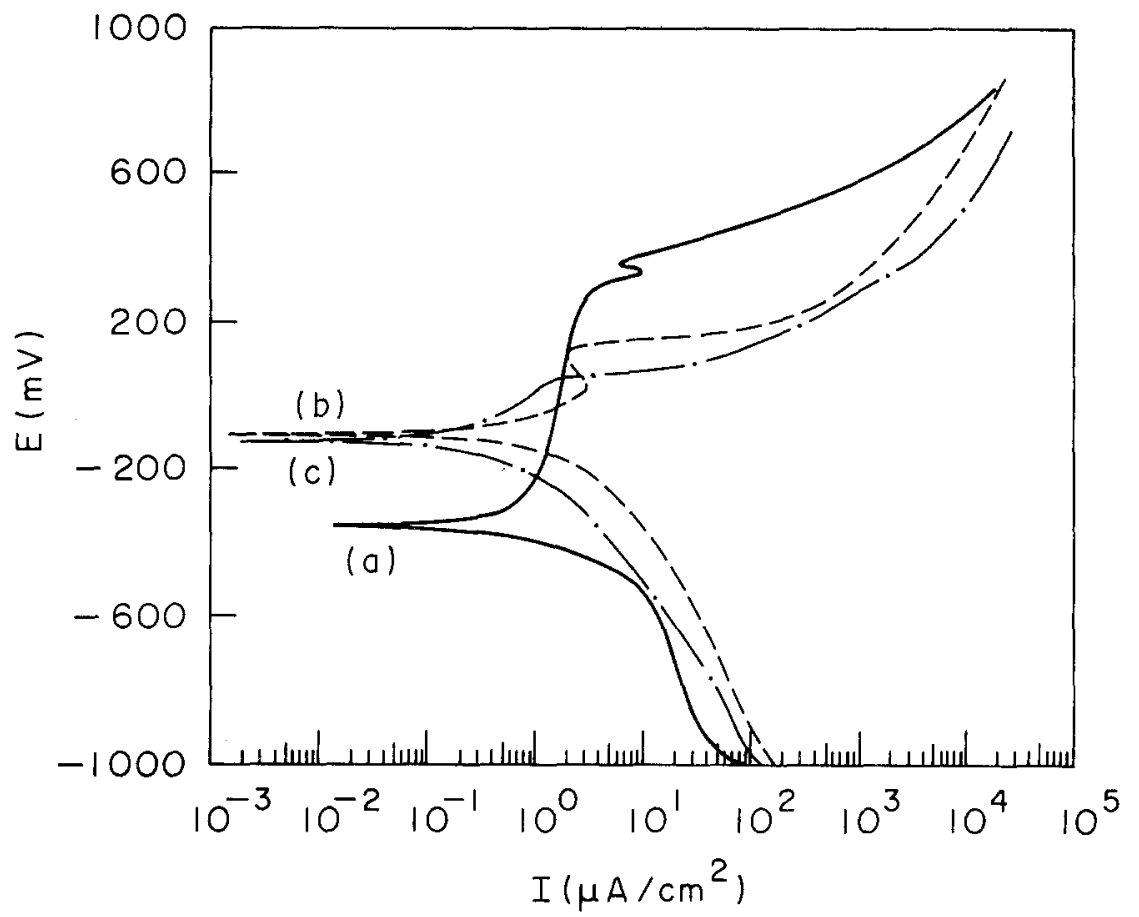

Fig. 1. Polarization curves recorded at $1 \mathrm{mV} / \mathrm{s}$ in aqueous $\mathrm{NaCl}, 100 \mathrm{~g} / \mathrm{dm}^{3}$ at room temperature for: (a) bare $316 \mathrm{~L}$ stainless steel, (b) coated with $\mathrm{ZrO}_{2}(0.5 \mu \mathrm{m})$, and (c) coated with $\mathrm{ZrO}_{2}(0.7 \mu \mathrm{m})$. Potentials referred to SCE.

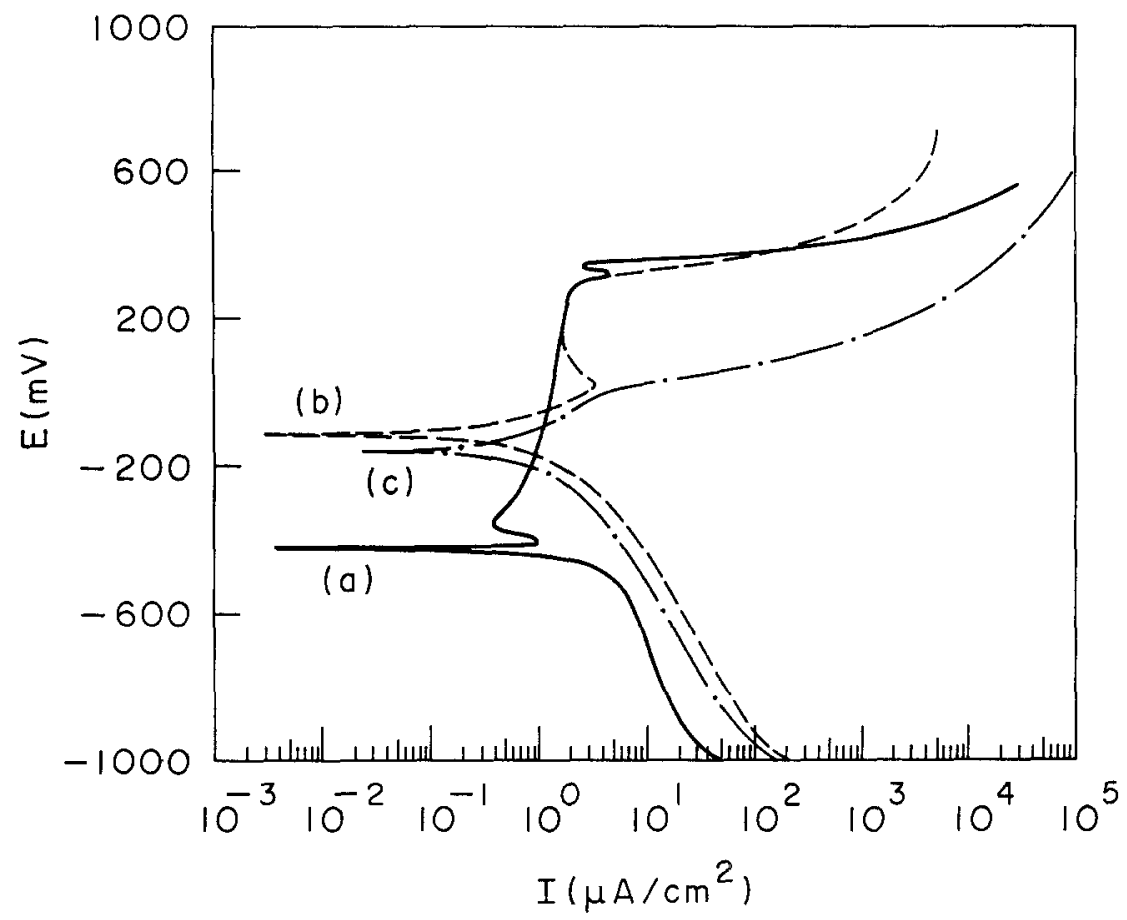

Fig. 2. Same as Fig. 1, but for aqueous $\mathrm{NaCl}, 200 \mathrm{~g} / \mathrm{dm}^{3}$ solution. 


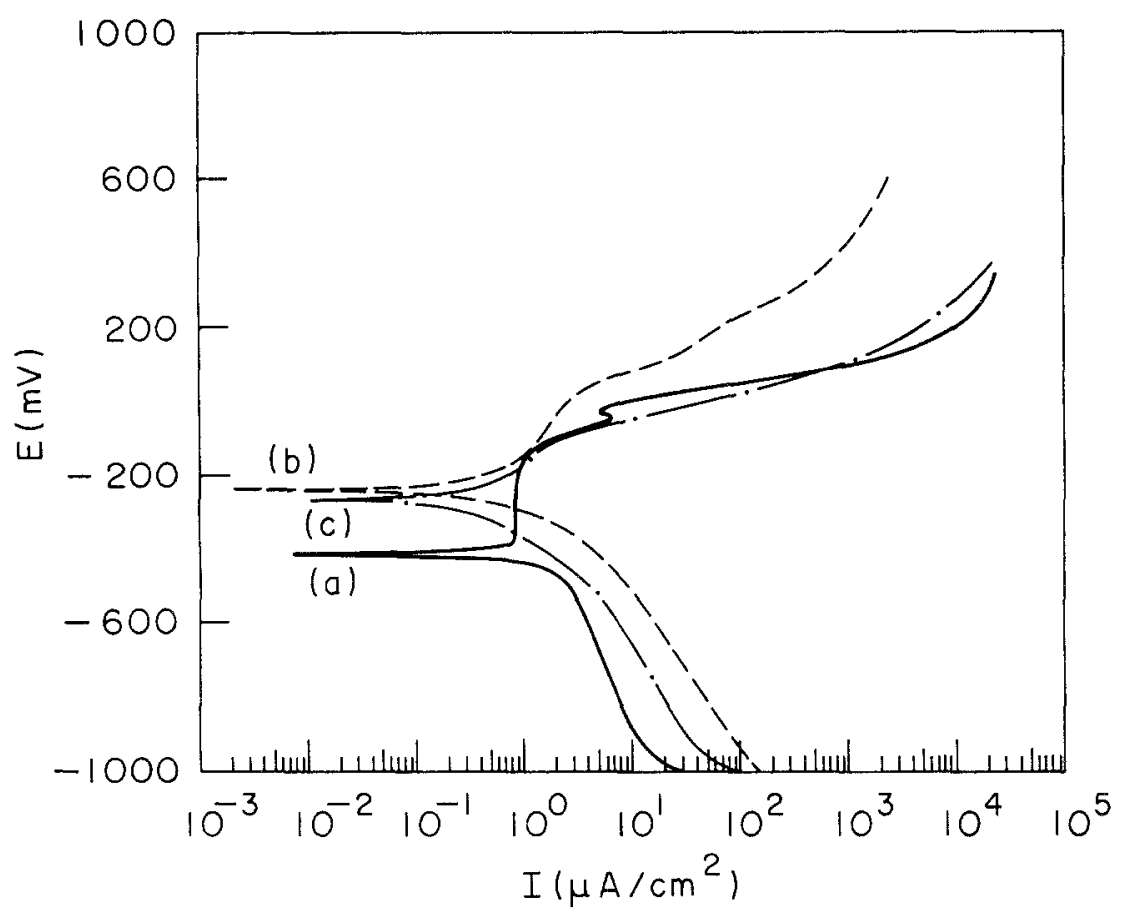

Fig. 3. Same as Fig. 1, but for acqueous $\mathrm{NaCl}, 300 \mathrm{~g} / \mathrm{dm}^{3}$ solution.

$\mathrm{NaCl}$ solutions.

Tables 1-3 collect the electrochemical parameters obtained from the polarization curves by means of the corrosion software employed. In all cases, the experiments were repeated several times, and the results reported for bare $316 \mathrm{~L}$ stainless steel and $\mathrm{ZrO}_{2}(0.5 \mu \mathrm{m})$ coatings correspond to mean values of at least three independent measurements which showed small variation (e.g., $\pm 5 \mathrm{mV}$ for $E_{\text {corr }}$ ). In the case of $\mathrm{ZrO}_{2}(0.7 \mu \mathrm{m})$ coatings, the results were not reproducible from sample to sample; some extreme results are presented in Tables 1 and 2 . Moreover, the correlation between the different parameters measured was not logical, indicating that the system under study was not properly defined. This must be a consequence of the cracks present in the coating.

Disregarding the results obtained for $\mathrm{ZrO}_{2}$ $(0.7 \mu \mathrm{m})$ coatings for the reason given above, Tables 1-3 show that the $\mathrm{ZrO}_{2}(0.5 \mu \mathrm{m})$ coatings have a profound effect on the corrosion behavior of $316 \mathrm{~L}$ stainless steel in aqueous $\mathrm{NaCl}$ solutions. First, the corrosion potential is shifted in the anodic direction by up to $300 \mathrm{mV}$, making the material more resistant to the attacks by the medium. Second, the value of the corrosion current shows large variations from experiment to experiment, dropping by a factor of 17 in one of the cases (Table 2). The combination of these results $\left(E_{\text {corr }}\right.$ and $i_{\text {corr }}$ ) suggest that the bare material with the $\mathrm{ZrO}_{2}$ coating will have a much longer useful life than without it. Meanwhile, experiments carried out using bare $316 \mathrm{~L}$ stainless steel plates heat-treated at $800^{\circ} \mathrm{C}$ for 2 hours showed that this procedure also alters the corrosion behavior of the steel, raising some doubts in relation to the material to which the comparisons should be made. To overcome this problem, efforts are being made to found conditions and appropriate additives that could allow lower temperatures in the densification steps of the $\mathrm{ZrO}_{2}$ coatings.

Comparison of the data at different $\mathrm{NaCl}$ concentrations is somewhat difficult since the solutions were air-saturated, meaning that $\mathrm{O}_{2}$ concentration will be lower for the more concentrated chloride solutions [42]. Nevertheless, 
Table 1. Electrochemical corrosion parameters derived from the polarization curves obtained at room temperature with an aqueous $\mathrm{NaCl}\left(100 \mathrm{~g} / \mathrm{dm}^{3}\right.$ test solution). $E_{\text {corr }}$ : corrosion potential (mV vs. SCE), $i_{\text {corr }}$ : corrosion current $\left(\mu \mathrm{A} / \mathrm{cm}^{2}\right), \mathrm{R}_{p}$ : polarization resistance $\left(\mathrm{k} \Omega \mathrm{cm}^{2}\right)$, C.R.: corrosion rate (mils per year, MPY).

\begin{tabular}{lcccc}
\hline Sample & $\begin{array}{c}-E_{\text {corr }} \\
(\mathrm{mV} \text { vs. SCE })\end{array}$ & $\begin{array}{c}i_{\text {corr }} \\
\left(\mu \mathrm{A} / \mathrm{cm}^{2}\right)\end{array}$ & $\begin{array}{c}\mathrm{R}_{p} \\
\left(\mathrm{k} \Omega \mathrm{cm}^{2}\right)\end{array}$ & $\begin{array}{c}\text { C.R. } \\
(\mathrm{MPY})\end{array}$ \\
\hline 316 L stainless steel & 339 & 0.48 & 62.6 & 0.26 \\
$\mathrm{ZrO}_{2}(0.5 \mu \mathrm{m})$ & 98 & 0.35 & 167.7 & 0.16 \\
$\mathrm{ZrO}_{2}(0.7 \mu \mathrm{m})$ & 112 & 0.20 & 384.8 & 0.09 \\
& 152 & 0.08 & 585.1 & 0.04 \\
\hline
\end{tabular}

Table 2. Same as in Table 1, but for aqueous $\mathrm{NaCl}\left(200 \mathrm{~g} / \mathrm{dm}^{3}\right)$ test solution.

\begin{tabular}{lcccc}
\hline Sample & $\begin{array}{c}-E_{\text {corr }} \\
\text { (mV vs. SCE) }\end{array}$ & $\begin{array}{c}i_{\text {corr }} \\
\left(\mu \mathrm{A} / \mathrm{cm}^{2}\right)\end{array}$ & $\begin{array}{c}\mathrm{R}_{p} \\
\left(\mathrm{k} \Omega \mathrm{cm}^{2}\right)\end{array}$ & $\begin{array}{c}\text { C.R. } \\
(\mathrm{MPY})\end{array}$ \\
\hline 316 L stainless steel & 418 & 4.85 & 18.8 & 2.27 \\
$\mathrm{ZrO}_{2}(0.5 \mu \mathrm{m})$ & 110 & 0.28 & 194.1 & 0.13 \\
$\mathrm{ZrO}_{2}(0.7 \mu \mathrm{m})$ & 295 & 0.80 & 144.3 & 0.37 \\
& 162 & 0.55 & 121.0 & 0.26 \\
\hline
\end{tabular}

Table 3. Same as in Table 1, but for aqueous $\mathrm{NaCl}\left(300 \mathrm{~g} / \mathrm{dm}^{3}\right)$ test solution.

\begin{tabular}{lcccc}
\hline Sample & $\begin{array}{c}-E_{\text {corr }} \\
(\mathrm{mV} \text { vs. SCE })\end{array}$ & $\begin{array}{c}i_{\text {corr }} \\
\left(\mu \mathrm{A} / \mathrm{cm}^{2}\right)\end{array}$ & $\begin{array}{c}\mathrm{R}_{p} \\
\left(\mathrm{k} \Omega \mathrm{cm}^{2}\right)\end{array}$ & $\begin{array}{c}\text { C.R. } \\
(\mathrm{MPY})\end{array}$ \\
\hline 316 L stainless steel & 415 & 2.21 & 14.3 & 1.04 \\
$\mathrm{ZrO}_{2}(0.5 \mu \mathrm{m})$ & 225 & 0.40 & 215.0 & 0.19 \\
$\mathrm{ZrO}_{2}(0.7 \mu \mathrm{m})$ & 260 & 0.31 & 90.0 & 0.14 \\
\hline
\end{tabular}


when the $\mathrm{NaCl}$ concentration increases, two apparently contradictory effects can be observed. The corrosion potentials move cathodically, but the corrosion currents (or rates) go through a maximum for the bare plates and through a minimum for the $\mathrm{ZrO}_{2}(0.5 \mu \mathrm{m})$ coatings. This must be a combination of the increment in chloride concentration, which makes the medium more aggressive, and the simultaneous depletion in $\mathrm{O}_{2}$ concentration, which decreases the rate of the prevailing cathodic reaction under these conditions. It also indicates that the electrochemical reactions occurring on both types of materials should be different; a detailed knowledge of this will require further studies. Apart from those effects, the overall results indicate once again that the $\mathrm{ZrO}_{2}$ coatings has an efficient protective role against the corrosion of $316 \mathrm{~L}$ stainless steel.

These findings qualitatively confirm previous observations [32, 33], where the corrosion behavior of similar samples was measured through weight gains in air and weight losses in $15 \%$ $\mathrm{H}_{2} \mathrm{SO}_{4}$ at elevated temperatures. However, the electrochemical techniques employed here are much more sensitive than the previous ones, and useful quantitative information can be obtained in short times.

\section{Conclusion}

With a single dip-coating procedure, crystalline films of $\mathrm{ZrO}_{2}$ with a tetragonal structure can be produced on $316 \mathrm{~L}$ stainless steel sheets. The results show that $\mathrm{ZrO}_{2}$ coatings of about $0.5 \mu \mathrm{m}$ in thickness provide an effective corrosion protection of these metal substrates in aqueous $\mathrm{NaCl}$ solutions. Thicker films present cracks after air densification at $800^{\circ} \mathrm{C}$ and are less protective.

\section{Acknowledgments}

This research was sponsored by FAPESP, FINEP, CNPq, CAPES/PICD, and the Program RHAENovos Materiais (Brazil).

\section{References}

1. C.J. Brinker and G.W. Scherer, Sol-Gel Science: the Physics and Chemistry of Sol-Gel Processing (Academic Press, San
Diego, 1990).

2. M.A. Aegerter, M. Jafelicci Jr., D.F. Souza, and E.D. Zanotto, ed., Sol-Gel Science and Technology (World Scientific, Singapore, 1991).

3. H. Dislich, in Sol-Gel Technology for Thin Films, Preforms, Electronics, and Specialty Shapes, edited by L.C. Klein (Noyes Publications, Park Ridge, 1988), p. 50.

4. R.B. Pettit, C.S. Ashley, S.T. Reed, and C.J. Brinker, in Sol-Gel Technology for Thin Films, Preforms, Electronics, and Specialty, edited by L.C. Klein (Noyes Publications, Park Ridge, 1988), p. 80.

5. S. Sakka, Reference 2, p. 346.

6. H. Schmidt, in Chemistry, Spectroscopy and Applications of Sol-Gel Glasses, edited by R. Reisfeld and C.K. Jorgensen (Springer-Verlag, Berlin, 1992), p. 119.

7. S. Sakka and T. Yoko, in Chemisty, Spectroscopy and Applications of Sol-Gel Glasses, edited by R. Reisfeld and C.K. Jorgensen (Springer-Verlag, Berlin, 1992), p. 90.

8. T. Yoko, K. Kamiya, A. Yuasa, K. Tanaka, and S. Sakka, J. Non-Cryst. Solids 100, 483 (1988).

9. T. Yoko, A. Yuasa, K. Kamiya, and S. Sakka, J. Electrochem. Soc. 138 8, (1991).

10. T. Yoko, A. Yuasa, K. Kamiya, K. Tanaka, and S. Sakka, Res. Rep. Fac. Eng. Mie Univ. 12, 41 (1987).

11. T. Yoko, K. Kamiya, K. Tanaka, and S. Sakka, Res. Rep. Bull. Chem. Res. Kyoto Univ. 67, 249 (1990).

12. T. Yoko, Y. Inagaki, and S. Sakka, Rep. Asahi Glass Foundation Ind. Techn. 13, 56 (1990).

13. J.D. Cairns, D.L. Segal, and J.L. Woodhead, Mat. Res. Soc. Symp. 32, 135 (1984).

14. G. Carturan, G. Facchin, G. Navaziv, V. Gottardi, and G. Cocco, in Ultrastructure Processing of Ceramics, Glasses and Composites, edited by L.L. Hench and D.R. Ulrich (J. Wiley, New York, 1984), p. 197.

15. A. Ueno, H. Suzuki, and Y. Kotera, J. Chem. Soc. Faraday Trans. 179, 127 (1983).

16. T. Ida, H. Tsuihi, A. Ueno, K. Tohki, Y. Udaga, K. Imai, and T. Sano, J. Catal. 106, 428 (1987).

17. S. Sakka, Catalysts 32, 2 (1990) (in Japanese).

18. J. Schlichting and S. Neumann, J. Non-Cryst. Solids 48, 185 (1982).

19. J. Martinsen, R.A. Figat, and M.W. Shafer, Mat. Res. Soc. Symp. Proc. 32, 361 (1984).

20. R.K. Brow and C.G. Pantano, Mat. Res. Soc. Symp. Proc. 32, 361 (1982).

21. S. Ogiwara and K. Kinugawa, Yogyo-Kyokai-Shi 90, 157 (1982) (in Japanese).

22. P.M. Glaser and C.G. Pantano, J. Non-Cryst. Solids 63, 209 (1984).

23. A. Makishima, H. Kubo, K. Wada, Y. Kitami, and T. Shimohira, J. Am. Ceram. Soc. 69, C127 (1986).

24. A. Makishima, M. Asami, and K. Wada, J. Non-Cryst. Solids 121, 310 (1990).

25. W. Beier, A.A. Göktas, and G.H. Frischat, J. Non-Cryst. Solids 100, 531 (1988).

26. C.W. Hsieh, A.S.T. Chiang, C.C. Lee, and S.J. Yang, J. Non-Cryst. Solids 144, 53 (1992).

27. S. Reed and C. Ashley, Mat. Res. Soc. Symp. Proc. 121, 631 (1988). 
28. O. de Sanctis, L. Gomez, N. Pelligri, C. Parodi, A. Marajofsky, and A. Duran, J. Non-Cryst. Solids 121, 338 (1990).

29. N. Tohge, A. Matsuda, and T. Minami, Chem. Express 2, 141 (1987).

30. M. Guglielmi, D. Festa, P.C. Innocenzi, P. Colombo, and M. Gobain, in Proc. Sixth International Workshop on Glasses and Ceramics from Gels, Seville 1991, J. Non Cryst. Solids 147-148, 474-477 (1992).

31. A.R. Di Giampaolo, M. Puerta, J. Lira, and N. Ruiz, in Proc. Sixth International Workshop on Glasses and Ceramics from Gels, Seville 1991, J. Non Cryst. Solids 147-148, 467473 (1992).

32. M. Atik and M.A. Aegerter, in Proc. Sixth International Workshop on Glasses and Ceramics from Gels, Seville 1991, J. Non-Cryst. Solids 147-148, 813-819 (1992).

33. M. Atik and J. Zarzycki, J. Mat. Sci. Lett., Accepted for publication.

34. A. Tomasi, P. Scardi and F. Marchetti, Mat. Res. Soc.
Symp. Proc. 271, 477-483 (1992).

35. M. Atik and M.A. Aegerter, Mat. Res. Soc. Symp. Proc. 271, 471-476 (1992).

36. D. Ganguli and D. Kundu, J. Mat. Sci. Lett. 3, 503 (1984).

37. N. Tohge, A. Matsuda, and T. Minami, J. Am. Ceram. Soc. 70, C13 (1987).

38. K. Izumi, H. Tanaka, Y. Uchida, N. Tohge, and T. Minami, in Proc. Sixth International Workshop on Glasses and Ceramics from Gels, Seville 1991, J. Non Cryst. Solids 147-148, 483-487 (1992).

39. R. di Maggio, P. Scardi, and A. Tomasi, Mat. Res. Soc. Symp. 180, 481 (1990).

40. M. Atik and J. Zarzycki (to be published).

41. A.J. Sedriks, Corrosion of Stainless Steels (John Wiley \& Sons, New York, 1979).

42. H.H. Uhlig and R.W. Revie, Corrosion and Corrosion Control, 3rd. Edition (John Wiley \& Sons, New York, 1985). 